\title{
La musealización del Monumento Proyecto para un centro de recepción de visitantes
}

\author{
Antonio Tejedor Cabrera \\ Mercedes Linares Gómez del Pulgar
}

Arquitectos

Al iniciar el proyecto de restauración de la Puerta de Córdoba, el I.A.P.H. estableció una estrategia de intervención dividida en tres fases operativas. La primera ha concluido con la ejecución de la restauración del monumento propiamente dicho; la segunda fase que se proponía en aquellos momentos consistía en la puesta en valor y la musealización, en el sentido de hacer comprensible el bien para el espectador mediante la explicación de sus valores en el propio edificio, a través de la incorporación de un nuevo uso que facilitara la interpretación de la Puerta en toda su compleja realidad histórica y arquitectónica.

Los objetivos básicos de esta segunda fase son: por un lado, recuperar los restos del podio romano excavados en la primera campaña arqueológica como medio de aproximación a la Puerta original; por otro, facilitar el acceso al ático, dentro de una visita selectiva al monumento, es decir en pequeños grupos, con la posibilidad de convertir la Puerta de Córdoba en un centro de interpretación territorial de Carmona que complete la oferta patrimonial y turística de la ciudad.

La ubicación de la Puerta en el escarpe del alcor, entre el Alcázar de Arriba y el Alcázar de la Reina, la convierten en un punto privilegiado de control visual del territorio que explica su extraordinario valor defensivo y estratégico en todas las épocas. Pero la disposición "encajada" entre dos escarpes de alcor y el crecimiento de la ciudad hasta los límites que establecía la presencia de la Puerta, acabaron por convertirla en un "objeto" que se podía atravesar aunque no visitar. Los espacios interiores de la Puerta, es decir, los dos pasajes laterales y el ático, sólo quedaron accesibles desde las casas colindantes que se adosaron al edificio con anterioridad a la intervención de finales del siglo XVIII, a la que debemos su imagen actual.
Por entonces, el arquitecto carmonense José de Echamorro reproduce simétricamente la disposición ligeramente oblicua de la fachada de la casa situada al norte en la nueva fachada del lado sur, generando un espacio urbano mejor acotado que potencia la simetría axial de la portada neoclásica así como la presencia urbana de la Puerta como fondo de la perspectiva. Consecuencia de la nueva ordenación fue la privatización de los espacios aledaños que, con el paso del tiempo, se convirtieron en espacios residuales de las viviendas utilizados como almacén de enseres.

El análisis realizado en los primeros croquis del proyecto permitió descartar cualquier tipo de acceso al ático por el lado de levante o desde las plataformas de alcor laterales, mediante escaleras y pasarelas, debido al fuerte impacto visual que tales actuaciones tendrían en la imagen del monumento. Al contrario, optamos por buscar alternativas que fueran poco agresivas e incluso pasaran desapercibidas para cualquier vecino de Carmona. De manera que la propuesta desarrollada parte de esta premisa de "invisibilidad" introduciendo la nueva pieza construida detrás de los muros existentes.

El proyecto presentado para la consecución de estos objetivos se desarrolla en una superficie de $50 \mathrm{~m}^{2}$ aproximadamente, en el lugar hoy destinado a garaje de la casa contigua a la Puerta por el lado meridional. El acceso se realizaría directamente desde la calle abriendo uno de los vanos fingidos que decoran la fachada de esta casa, que hemos atribuido al autor de las portadas neoclásicas de la Puerta de Córdoba, José de Echamorro. La cota de acceso impone el nivel del suelo interior que queda ligeramente por encima de la cota arqueológica original correspondiente a la Puerta romana. La recuperación completa del podio de la fachada romana permitirá la incorporación parcial de la imagen de esta época al espacio de recepción de visitantes.

Para reforzar el carácter de fachada de este lienzo, que habrá que restaurar, la cubierta de la sala se concibe como un lucernario que permite la iluminación natural de este paramento exterior del edificio 
El proyecto de Musealización de la Puerta de Córdoba pretende facilitar al espectador una lectura completa del importante papel territorial que el Bien tuvo desde sus orígenes en relación con el control de la Vega del río Corbones, que explica el carácter monumental y propagandístico de la Puerta romana y la dimensión paisajística que hoy en día conserva.

del siglo I. Frente a esta fachada, y, por tanto, en la posición más alejada posible de la misma, se desarroIla la escalera que permite el acceso de los visitantes a la parte alta de la Puerta, donde es posible el uso de los adarves y las cubiertas de los torreones como miradores. Con ello se consigue facilitar al espectador una lectura completa del importante papel territorial que la Puerta de Córdoba tuvo desde sus orígenes en relación con el control de la Vega del río Corbones, que explica el carácter monumental y propagandístico de la Puerta romana y la dimensión paisajística que hoy en día conserva. La visita al ático neoclásico permitirá explicar, mediante el programa museográfico adecuado, las transformaciones acontecidas en el devenir histórico de la Puerta hasta la construcción de su última imagen ilustrada a finales del siglo XVIII. De manera que el Centro de Recepción queda constituido por tres espacios: un balcón al paisaje y dos salas, una a nivel de calle y otra a nivel de ático.

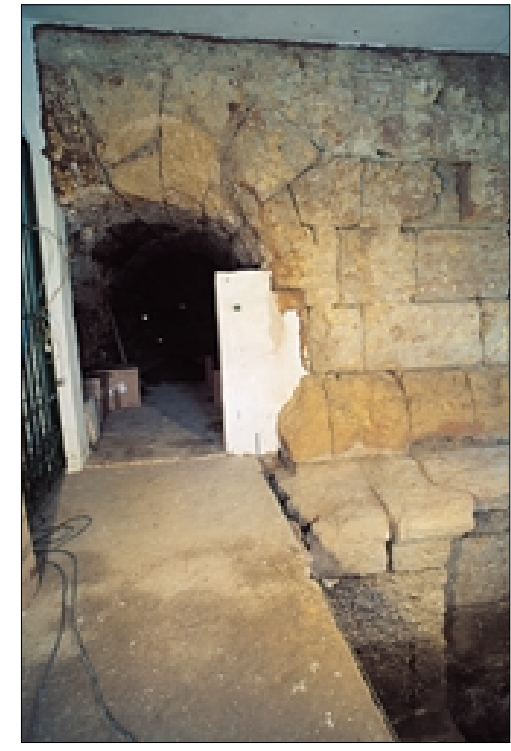

Lienzo y podio correspondientes a la fachada occidental de la puerta romana

Maqueta de la Puerta de Córdoba con la ubicación del Centro de Recepción

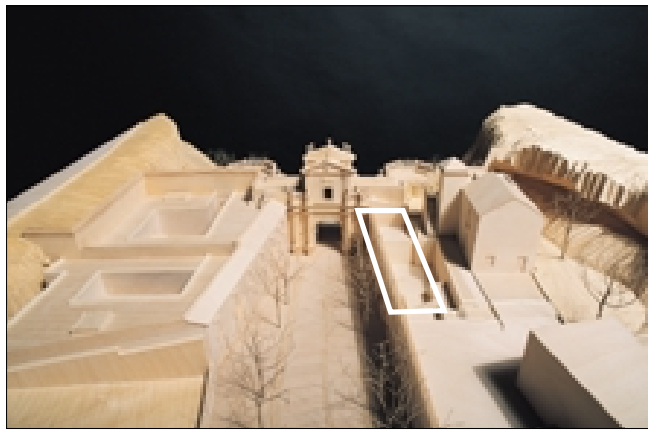

\section{Plantas del Centro de Recepción}
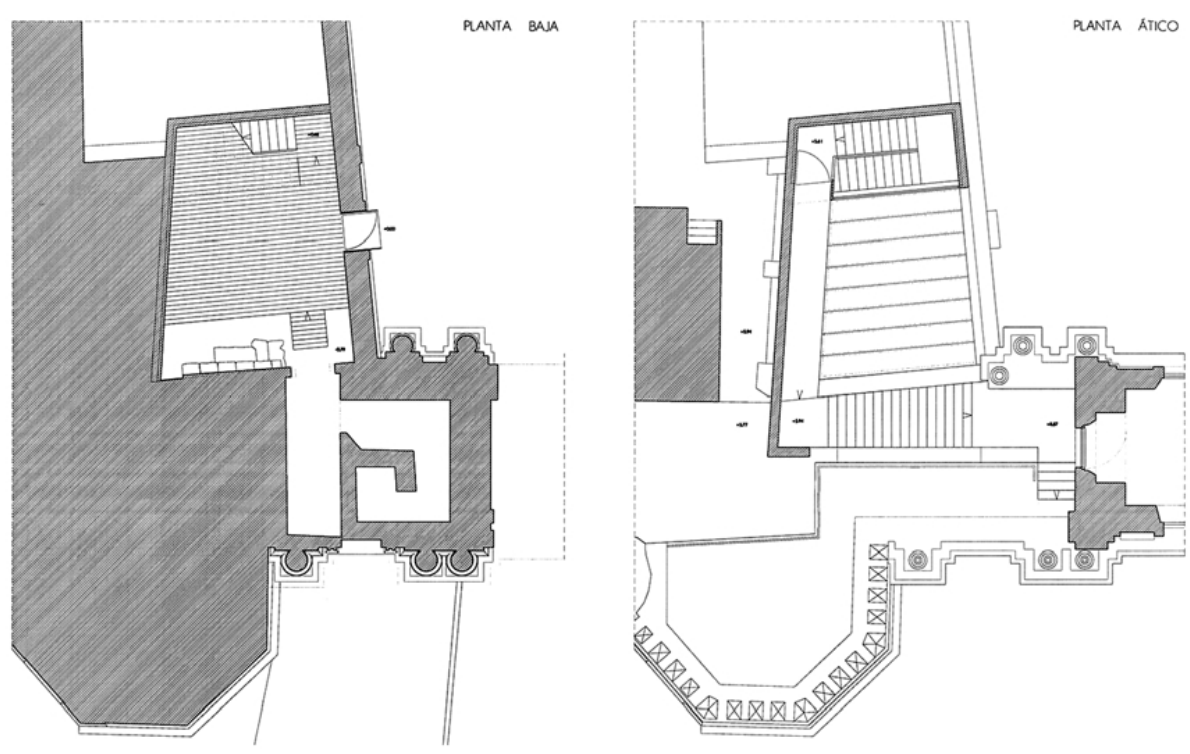

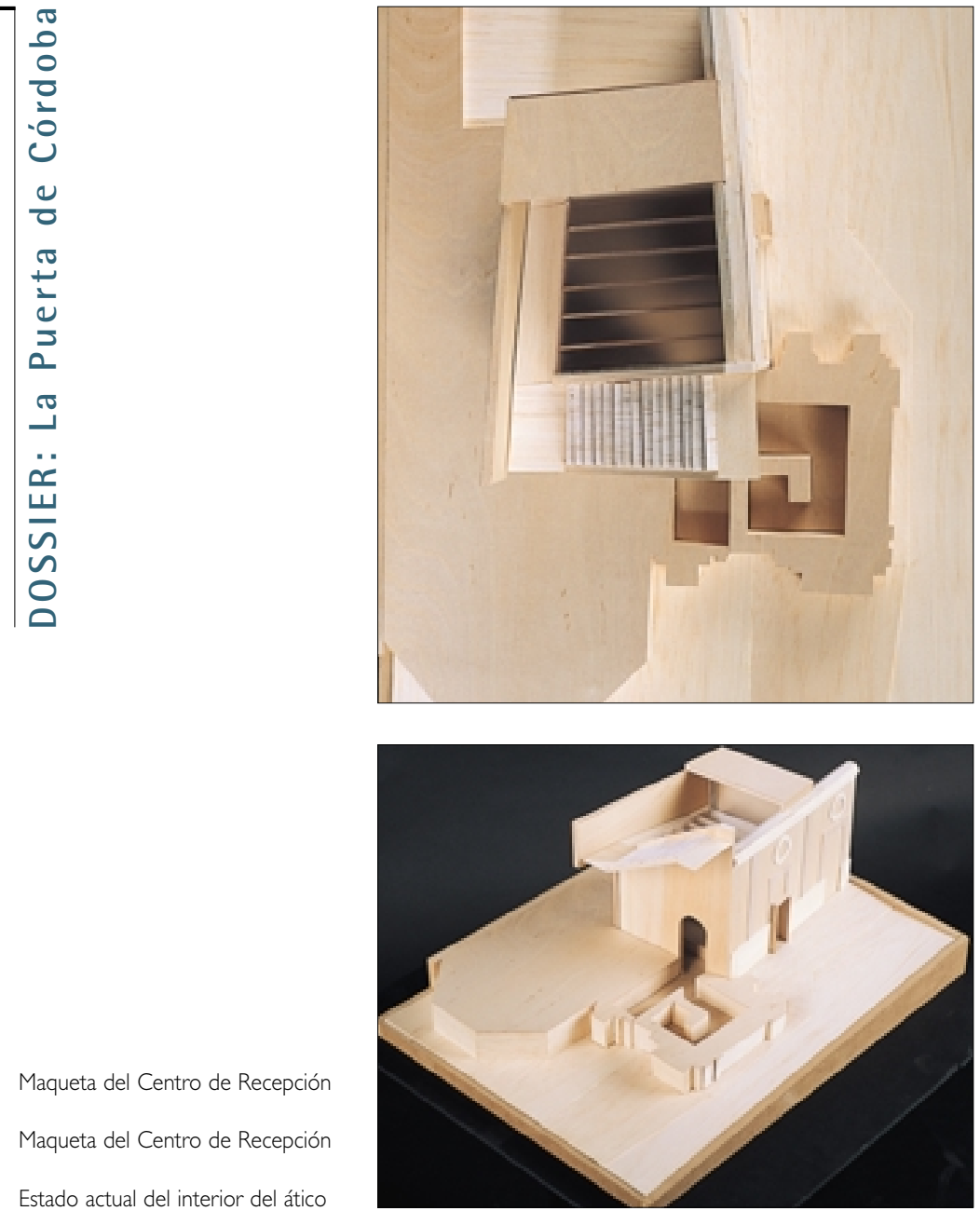

Estado actual del interior del ático

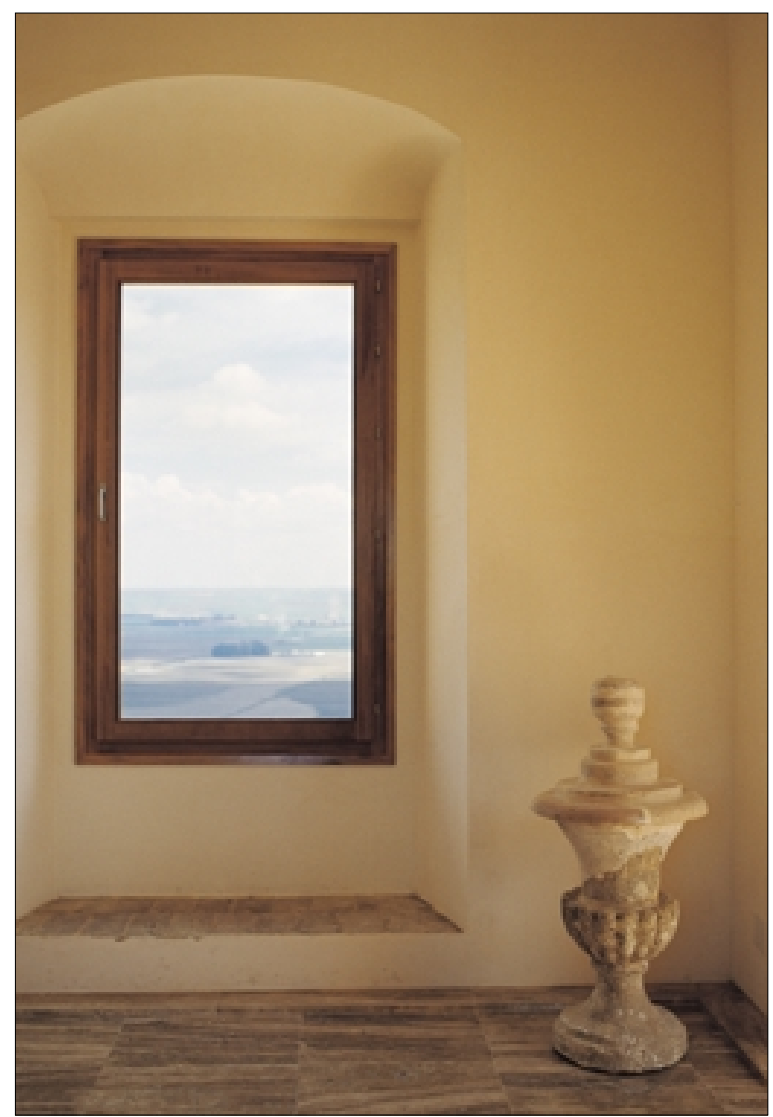

Anticipándonos a este proyecto, la restauración del interior del ático se ha planteado como pequeño espacio expositivo, complementario de la sala inferior, destinada a la presentación de la Puerta en sus distintas etapas conocidas en época moderna y contemporánea, incluso con alguna referencia a la restauración concluida en 2000. El uso de la sala se ha hecho explícito ya en esta obra musealizando un jarrón de remate que pertenece a la propia Puerta y que representa simbólicamente la transformación estilística que sufrió doscientos años atrás.

La intervención propuesta para la sala inferior quedará totalmente diferenciada de las estructuras originales mediante una cierta neutralidad formal. Se utilizarán materiales nobles (piedra natural, madera, revocos de cal, etc.) y poco elaborados formalmente para crear un espacio neutro que permita la revalorización de los restos romanos y facilitar el mantenimiento del edificio. La excavación con metodología arqueológica del pasaje meridional permitirá visitar el espacio ocupado por la escalera que servía de acceso al cuerpo de guardia de la Puerta romana. El suelo de este pasaje quedará terrizo rescatándose, si existen, los pavimentos y alfeizares originales. Por su parte el pavimento de la sala será un entarimado de madera que se pliega bajo la escalera para conformar una pequeña grada que permita el asiento del público. Desde ella se podrán contemplar los restos arqueológicos y escuchar una explicación sobre los mismos. Está previsto también dotar al espacio de las instalaciones adecuadas a las necesidades expositivas: iluminación, sistemas de telecomunicaciones y multimedia, seguridad contra intrusos, protección contra incendios, etc.

A la segunda fase seguiría el proyecto de recuperación paisajística del entorno de la Puerta de Córdoba, dentro de esta visión integral de restauración que pretendemos aplicar sobre el monumento, en la que el tratamiento de los espacios afectados por su cuenca visual es tan importante como la restauración del propio edificio. Los contenidos de esta tercera fase ya fueron enunciados en el proyecto de restauración (I ${ }^{\text {a }}$ fase) y pueden considerarse, si cabe, más ambiciosos que éste último dadas las escasas ocasiones en que, en nuestro ámbito geográfico, la restauración de los monumentos ha venido seguida de la restauración del paisaje en el que se insertan, con lo que ello significa de ruptura de inercias y viejos prejuicios.

Con tintes tan dramáticos como el estado de conservación en que se encontraba la Puerta en 1995, podemos referirnos a la aparición del vertedero que, en pocos años, modificó la topografía de la vaguada delantera y acabó consolidado con la obra de pavimentación acometida en los primeros años 90. Quedó así truncada cualquier posibilidad de visión lejana del monumento sin que éste se viera literalmente segado por la presencia de los escombros. La recuperación del perfil natural de la vaguada es la apuesta fundamental de esta tercera fase que se verá acompañada de otras actuaciones 


\section{Secciones hacia el Este y el Sur}

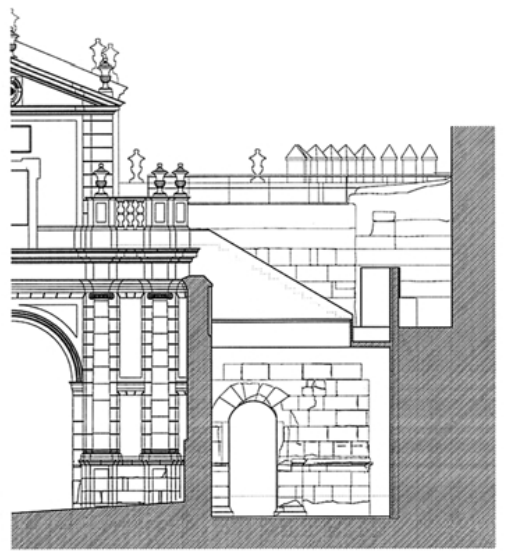

SECCION ESTE

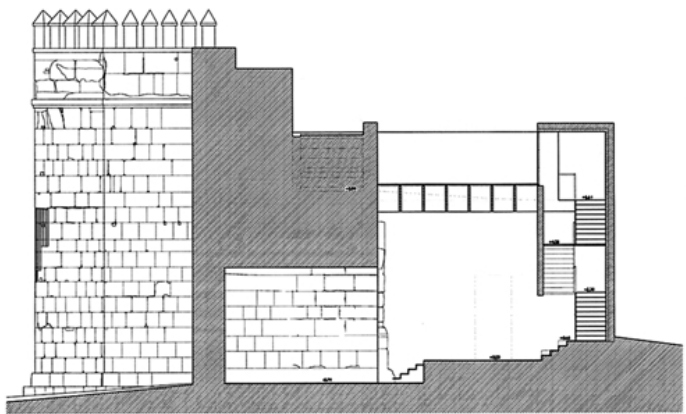

SECCION SR

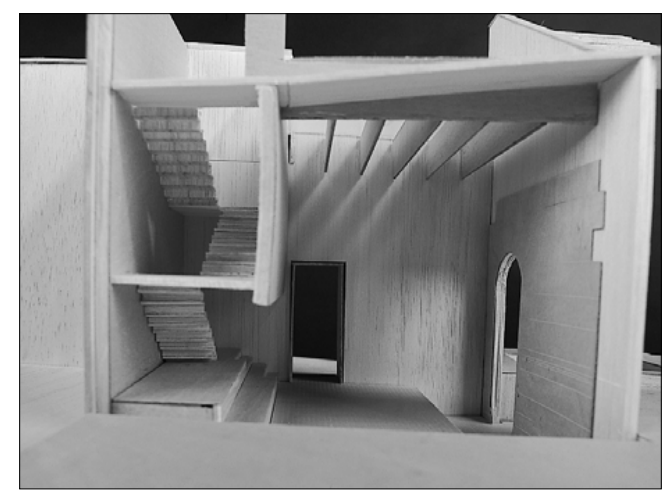

asentamientos que jalonan la carretera de acceso por el sur, de los tendidos eléctricos que cruzan a unas decenas de metros de la fachada y del inservible castillete de la casa contigua que asoma por encima de la Puerta cuando se la contempla desde cierta distancia.

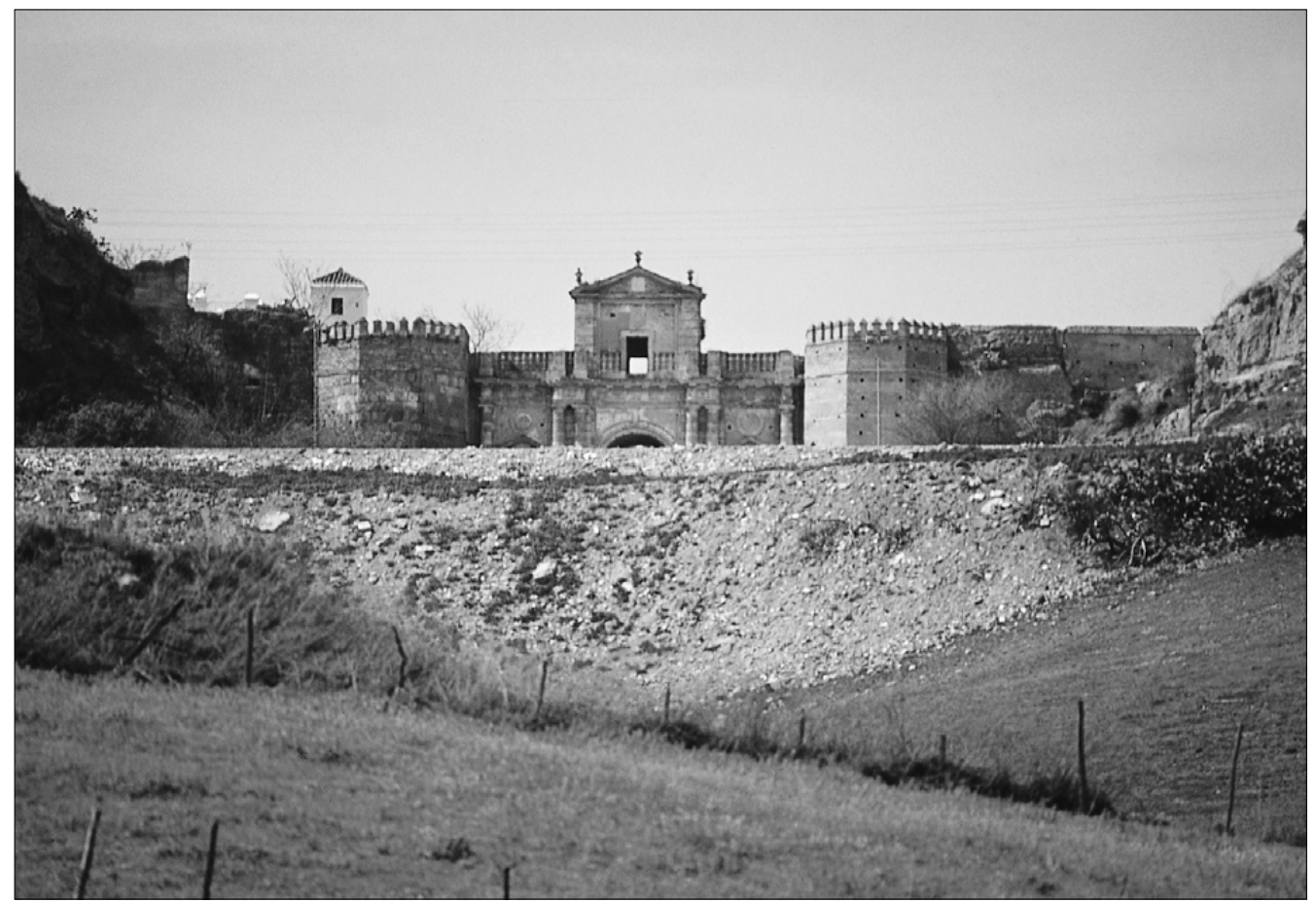

Vista lejana de la Puerta de Córdoba "seccionada" por el vertedero

Interior de la sala inferior. Maqueta

destinadas a generar el adecuado marco paisajístico zada que organizaba el tránsito por el sur de la Bérestos de esta calzada romana y del "Puente d actualidad) constituyen intervenciones esenciales de

Por último, otras actuaciones complementarias sera consolidación del alcor en los tramos contines de arbolado y vegetación autóctona en la ladera, y la nueva iluminación monumental tanto de la Puerta como de la calzada y el puente. Todas estas actuaciones sobre el entorno deberán ir acompañadas de la eliminación de los cobertizos y los 